\title{
Characterization of Episomal Replication of Bovine Papillomavirus Type 1 DNA in Long-Term Virion-Infected Saccharomyces Cerevisiae Culture
}

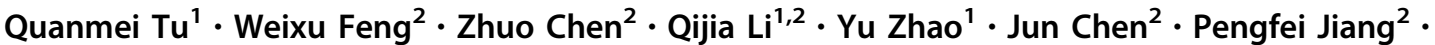 \\ Xiangyang $\mathrm{Xue}^{2} \cdot$ Lifang Zhang $^{2}$ (i) $\cdot$ Kong-Nan Zhao ${ }^{1,2,3}$ (1)
}

Received: 22 February 2021 / Accepted: 21 May 2021 / Published online: 30 August 2021

(C) The Author(s) 2021

\begin{abstract}
We have previously reported that bovine papillomavirus type 1 (BPV-1) DNA can replicate its genome and produce infectious virus-like particles in short term virion-infected S. cerevisiae (budding yeast) cultures (Zhao and Frazer 2002, Journal of Virology, 76:3359-64 and 76:12265-73). Here, we report the episomal replications of BPV-1 DNA in long term virion-infected S. cerevisiae culture up to 108 days. Episomal replications of the BPV-1 DNA could be divided into three patterns at three stages, early active replication (day 3-16), middle weak replication (day 23-34/45) and late stable replication (day 45-82). Two-dimensional gel electrophoresis analysis and Southern blot hybridization have revealed further that multiple replication intermediates of BPV-1 DNA including linear form, stranded DNA, monomers and higher oligomers were detected in the virion-infected yeast cells over the time course. Higher oligomers shown as covalently closed circular DNAs (cccDNAs) are the most important replication intermediates that serve as the main nuclear transcription template for producing all viral RNAs in the viral life cycle. In this study, the cccDNAs were generated at the early active replication stage with the highest frequencies and then at late stable replication, but they appeared to be suppressed at the middle weak replication. Our data provided a novel insight that BPV-1 genomic DNA could replicate episomally for the long period and produce the key replication intermediates cccDNAs in S. cerevisiae system.
\end{abstract}

Keywords Bovine papillomavirus type 1 (BPV-1) - Saccharomyces cerevisiae · Genomic DNA replication · Agarose gel electrophoresis · Southern blot hybridization

Supplementary Information The online version contains supplementary material available at https://doi.org/10.1007/ s12250-021-00439-y.

Kong-Nan Zhao

knzhao888@hotmail.com; k.zhao@uq.edu.au

Lifang Zhang wenzhouzlf@126.com

1 Department of Obstetrics and Gynaecology, The Second Affiliated Hospital and Yuyin Children Hospital of Wenzhou Medical University, Wenzhou 325035, China

2 Institute of Molecular Virology and Immunology, Department of Microbiology and Immunology, School of Basic Medical Sciences, Wenzhou Medical University, Wenzhou 325035, China

3 Australian Institute for Bioengineering and Nanotechnology, the University of Queensland, St Lucia 4067, Australia

\section{Introduction}

Papillomaviruses (PVs) are a family of small doublestranded circular DNA viruses with more than 200 genotypes (Doorbar 2016). Human papillomaviruses (HPVs) have been demonstrated to be responsible for causing several human cancers and genital warts (Moody and Laimins, 2010). The persistent infection of high-risk human papillomavirus (hr-HPV) is closely related to the pathogenesis of cervical cancer and many other cancers. Indeed, HPVs account for more than $30 \%$ of all infectionassociated cancers in humans (zur Hausen 2009). Preventive vaccines including 2 -valent, 4-valent and 9-valent vaccines against HPV-associated cervical cancer are now available, which prevent an estimated $92 \%$ of the cancers attributable to HPV types (Frazer and Levin 2011; Huh et al. 2017; Zhang et al. 2020a). Considering that the preventive vaccines are unable to wipe out the existing 
HPV viruses in already infected people, scientists have been focusing on developing therapeutic HPV vaccines that have reached the clinical trial phase in cervical cancers and diseases. Many therapeutic HPV vaccines tested in clinical trials show the potential use of the vaccines as safe and effective pharmacological tools (Ding et al. 2010; Zhang et al. 2020a; Zhao et al. 1998; Zottnick et al. 2020). Recently, published studies have revealed that HPV minor capsid L2 proteins play a crucial role in the early stage of HPV infection (DiGiuseppe et al. 2015; Gagnon et al. 2015; Zhang et al. 2018, 2020b). The C terminus of HPV L2 proteins contains a short sequence of basic amino acids serving as a cell-penetrating peptide (CPP) (Campos 2017; DiGiuseppe et al. 2015; Zhang et al. 2018). The CPP binds to a cytoplasmic trafficking factor, retromer, thereby sorting the virus into the retrograde pathway for properly trafficking the incoming virus to the nucleus, the site of viral gene expression and DNA replication (Campos 2017; DiGiuseppe et al. 2015; Zhang et al. 2018). Thus, it appears that there is a need for specific drugs for targeting the CPP of L2 proteins to prevent HPV infection potentially leading to the development of HPV therapy against HPV-induced cancer.

PVs have also been identified in most domestic animals such as bovines (BPVs), canines (CPVs), goats (Capra hircus papillomavirus-ChPVs), equines (Eqnus caballus papillomavirus EcPVs) (Modolo et al. 2017). BPVs are the most typical animal PVs, which are a cosmopolitan virus, worldwide distributed, independently of the level of expertise on livestock exploration (Araldi et al. 2017). BPVs containing 15 types have been classified into 3 separate genera: Deltapapillomavirus, Epsilonpapillomavirus, and Xipapillomavirus, which are causative agents of benign and malignant tumors in cattle, such as cutaneous papilloma, fibropapilloma, urinary bladder and esophageal cancers (Borzacchiello and Roperto 2008; Campo 2003; Munday et al. 2015). BPV-1, BPV-2, and BPV-13, for example, are classified in the Deltapapillomavirus genus and induce fibropapilloma (Munday et al. 2015; Thomson et al. 2015). Since 1970, BPV-1 has been used as a prototype papillomavirus to study PV biology and oncology (Araldi et al. 2017; Borzacchiello and Roperto 2008; Borzacchiello et al. 2006; Koller and Olson 1972). As a model system, BPV-1 has been used to study the regulation of DNA replication in higher eukaryotes (Schvartzman et al. 1990). In addition, transcription of BPV-1 viral RNAs has been previously reported in BPV-1 transformed cells and in warts (Amtmann and Sauer, 1982). The study of using BPV has greatly improved our understanding of HPV-associated carcinogenesis (Munday et al. 2015). We and others have previously developed an in vitro Saccharomyces cerevisiae (budding yeast) system, which is permissive for viral DNA replication (e.g. BPV-1 and different types of HPVs) (Angeletti et al. 2002; Zhao and Frazer 2002a, b). We discovered that $S$. cerevisiae was infected with BPV-1 virions isolated from the bovine papilloma leading to not only the replication of BPV-1 genomic DNA, but also the production of infectious viruslike particles (Zhao and Frazer 2002a, b). The use of $S$. cerevisiae for the replication of both plant and animal viruses was a breakthrough (Navarro et al. 2004).

Several studies have reported the replication patterns of PV genome in different systems by means of different techniques such as Southern blot, chromogenic in situ hybridization (CISH) and PCR using specific and/or degenerate primers (Araldi et al. 2015; Melo CA and Melo SA, 2014; Melo et al. 2015). In addition, using the restriction fragment length polymorphism of PCR products (PCR-RFLP) allows to identify BPV type (Carvalho et al. 2013), since this method shows a correlation of $95 \%$ with the results obtained using DNA sequencing (Carvalho et al. 2013; Kawauchi et al. 2015). However, the above methods cannot be used to characterize the replication mode and intermediates of the viral DNA that persists as extrachromosomal plasmids in eukaryotic cells and neither to resolve the initiation, elongation, and termination of DNA replication associated with distinct, nonlinear DNA structures. Bell and Byers first developed two-dimensional agarose gel electrophoresis (2-DAGE) to study the shape of DNA recombination intermediates (Bell and Byers 1983). The 2-DAGE includes a first and a second (run perpendicular to the first) dimension agarose gel electrophoresis. The first dimension is a conventional separation of DNA by molecular size. The second dimension is to separate the molecules mainly on the basis of the DNA shape. Since then, 2-DAGE has been proved to be highly advanced and useful for studying the complex topological problem of DNA replication. The rationale and advances of 2-DAGE for DNA replication study include: (1) mapping origins and termination sites of DNA replication; (2) investigating the efficiency of different origins and the progress of DNA replication forks along DNA fragments; (3) determining the activity level of putative replication origin-containing sequences; (4) analyzing replication timing, fork progression, fork pausing, fork stalling and collapse, termination, and recombinational repair; and (5) resolving the nonlinear, replicating DNA molecules from the linear, nonreplicating molecules (Dandjinou et al. 2006; Lemacon et al. 2017; Makovets 2013; Olavarrieta et al. 2002; Quinet et al. 2017). Indeed, Schvartzman et al. identified extrachromosomal forms of BPV-1 DNA replication in viral DNAtransformed ID13 cells by 2-DAGE (Schvartzman et al. 1990). We have also observed a single replication bubble of BPV-1 DNA in short-term virion-infected S. cerevisiae cultures by 2-DAGE (Zhao and Frazer 2002a). 
Although multiple HPV genomes replicate stably in $S$. cerevisiae for a long-term (up to $75 \mathrm{~h}$ ), but they differ in replication efficiency (Rogers et al. 2008). The patterns of PV DNA replication and the replication intermediates in S. cerevisiae remain unknown. Thus, we proposed to study the episomal replication patterns and intermediates of BPV-1 DNA in long-term virion-infected $S$. cerevisiae cultures (up to 108 days) by means of one- and two-dimensional gel electrophoresis and Southern blot hybridization. As an attempt to use BPV-1 model, we studied the regulation of DNA replication in a latently virion-infected single-celled eukaryotic organism. The obtained data have highlighted the characteristics of BPV-1 genomic DNA giving some insights of virus infection in $S$. cerevisiae system although the exact mechanism of BPV-1 DNA replication remains unclear.

\section{Materials and Methods}

\section{BPV-1 Virion Preparation}

BPV-1 virions used for $S$. cerevisiae protoplast infection were prepared from bovine papilloma as reported previously (Zhao and Frazer 2002a, b). Virions in suspension were dialyzed against $0.15 \mathrm{~mol} / \mathrm{L}$ phosphate-buffered saline (PBS) (pH 7.4) for $30 \mathrm{~min}$ and then used to infect $S$. cerevisiae protoplasts.

\section{Cultures of BPV-1-Infected S. cerevisiae Cells and Sample Collection}

BPV-1-infected S. cerevisiae cells were grown in vitro for a long-term culture, similar to our previous description (Zhao and Frazer 2002a, b), with some modifications. Briefly, S. cerevisiae protoplasts $\left(10 \mathrm{~mL} ; 5 \times 10^{7}\right.$ cells/ $\mathrm{mL}$ ) infected with $0.6 \mu \mathrm{g}$ of BPV-1 virions was grown in $S$. cerevisiae medium containing $0.8 \mathrm{~mol} / \mathrm{L}$ sorbitol and $0.2 \mathrm{~mol} / \mathrm{L}$ glucose on a shaker with gentle agitation at $28{ }^{\circ} \mathrm{C}$ in the dark for three separate long time courses (82, 85 and 108 days). S. cerevisiae protoplasts without infection of BPV-1 virions were cultured under the same condition as a negative control. Ten to twelve time points were designed to collect $S$. cerevisiae cells for analysis of viral DNA replication. At each time point, $5 \mathrm{~mL}$ of $S$. cerevisiae cells was collected and allocated for Hirt supernatant DNA (Hirt DNA), RNA and protein preparation, with $5 \mathrm{~mL}$ of fresh medium without sorbitol added for continuous culture.

\section{Hirt DNA Preparation}

BPV-1-infected S. cerevisiae cultures were used for the preparation of Hirt DNA as described. Digestion of $S$. cerevisiae cells with enzyme was the same as that for $S$. cerevisiae protoplast preparation. The digested S. cerevisiae cells were washed with $1 \mathrm{~mol} / \mathrm{L}$ sorbitol and lysed in $400 \mu \mathrm{L}$ of lysate buffer $(10 \mathrm{mmol} / \mathrm{L}$ Tris $-\mathrm{HCl}, \mathrm{pH} 7.5$, $10 \mathrm{mmol} / \mathrm{L}$ EDTA, and $0.2 \%$ Triton $\mathrm{X}-100$ ) at $25^{\circ} \mathrm{C}$ for $10 \mathrm{~min}$. Then $100 \mu \mathrm{L}$ of $5 \mathrm{~mol} / \mathrm{L} \mathrm{NaCl}$ was added to the lysate, and the mixture was frozen at $-20^{\circ} \mathrm{C}$ for $40 \mathrm{~min}$. The frozen lysates were thawed at $25{ }^{\circ} \mathrm{C}$ for $20 \mathrm{~min}$. The resultant supernatants containing viral DNA (Hirt DNA) were incubated with $100 \mu \mathrm{g}$ of proteinase $\mathrm{K}$ at $37{ }^{\circ} \mathrm{C}$ for $1 \mathrm{~h}$. The Hirt DNA was extracted with Tris-buffered phenol twice and chloroform once and then precipitated by ethanol. The Hirt DNA was then used for agarose gel electrophoresis and Southern blot hybridization.

\section{One-Dimensional Agarose Gel Electrophoresis and Southern Blot Hybridization}

Hirt DNA $(10 \mu \mathrm{g})$ partially digested with Hind III as previously reported (Zhao and Frazer 2002a, b) was electrophoresed on a $1 \%$ one-dimensional agarose gel electrophoresis (1-DAGE), then blotted onto nylon membranes, and hybridized with a ${ }^{32} \mathrm{P}$-labeled BPV-1 DNA probe (Zhao and Frazer 2002a).

\section{Two-Dimensional Agarose Gel Electrophoresis and Southern Blot Hybridization}

Hirt DNA $(15 \mu \mathrm{g})$ without enzyme digestion as reported by Schvartzman and colleagues (Schvartzman et al. 1990) was separated on a neutral/alkaline 2-DAGE. The Hirt DNA was electrophoresed on a first-dimension agarose gel $(0.4 \%)$ in TAE buffer $(40 \mathrm{mmol} / \mathrm{L}$ Tris-acetate, $2 \mathrm{mmol} / \mathrm{L}$ EDTA, $\mathrm{pH} 8.0$ ) at $1.5 \mathrm{~V} / \mathrm{cm}$ for $20 \mathrm{~h}$. The DNA lanes were run on a second-dimension agarose gel $(1.0 \%$ agarose in sterile distilled $\mathrm{H}_{2} \mathrm{O}$ ) in alkaline electrophoresis buffer ( $40 \mathrm{mmol} / \mathrm{L} \mathrm{NaOH}, 2 \mathrm{mmol} / \mathrm{L}$ EDTA) at $1.5 \mathrm{~V} / \mathrm{cm}$ for $24 \mathrm{~h}$ and then blotted onto nylon membranes. The DNA blots were hybridized with a ${ }^{32} \mathrm{P}$-labeled BPV-1 DNA probe that was a linearized BPV genome to detect all the replication intermediates (Zhao and Frazer 2002a, b). According to previous studies (Flores and Lambert 1997; Sakakibara et al. 2013; Schvartzman et al. 1990), the replication mode and intermediates of the BPV-1 DNA in $S$. cerevisiae were analyzed and identified. The replication intermediates included single-stranded DNA (1ss), doublestranded DNA (2ss), heterogeneous double-stranded DNA (hds), linear forms (lin) and a series of oligomers. 
Replication intermediates also included recombinant-dependent replication (RDR), rolling circle replication (RCR) and conspicuous multimeric circular ssDNA (cms). A diagram drawn from the visualized Southern blot hybridization results was used to explain in details the identified replication intermediates of BPV-1 DNA occurred in S. cerevisiae cells in Result section.

\section{Results}

\section{Episomal Replication of BPV-1 DNA in Long-Term Virion-Infected S. cerevisiae Cultures}

We previously demonstrated that BPV-1 DNA could be detected in a small volume $(2 \mathrm{~mL})$ of $S$. cerevisiae cells infected with BPV-1virions at day 55 and 75 post-infection by 1-DAGE and Southern blot hybridization of Hirt DNA (Zhao and Frazer 2002a, b). Thus, to confirm further that BPV-1 DNA could be persistently present in the BPV-1infected $S$. cerevisiae cells in a relatively large volume $(10 \mathrm{~mL})$ cultured for a longer period at $28{ }^{\circ} \mathrm{C}$, we carried out three separate long term BPV-1 virion-infected S. cerevisiae culture experiments up to 108 days. It was observed that the BPV-1-infected S. cerevisiae cells grew slowly from day $23 / 34$ to day 45 and most of the cells showed unhealthy morphology (Supplementary Fig. S1). We prepared Hirt DNA from the long term BPV-1-infected $S$. cerevisiae cultures at various time points to investigate whether and how BPV-1 DNA was present by Southern blot analysis. The Hirt DNA was subjected to partial digestion with HindIII, which should cut BPV-1 DNA at a single site. The partial-digested Hirt DNA hybridized with BPV-1 DNA revealed that BPV-1 DNA was detected in all three long-term BPV-1-infected $S$. cerevisiae cultures (Fig. 1). The present forms of BPV-1 DNA in the longterm BPV-1-infected $S$. cerevisiae cultures varied distinctly from the early stage to the late stage (Fig. 1). At the early stage (day 3 to day 16/23), three bands of the BPV-1 DNA were observed to correspond to nicked circular, linear, and supercoiled monomeric BPV-1 DNA although the signals of nicked circular form were very weak. At the middle and late stages (day 23 to day 82), nicked circular form was undetectable, while signals of the other two forms decreased significantly at day 23/34 then at a constant level. Compared with the nicked circular and supercoiled monomeric forms, the linear BPV-1 DNA had the strongest signals over the time period (Fig. 1A), which could be attributed to the partial digestion of HindIII. The present patterns of BPV-1 DNA detected in the three long-term BPV-1-infected $S$. cerevisiae cell cultures were generally similar, but the signals of nicked circular and supercoiled forms differed (Fig. 1). The results confirmed that
A Time course one

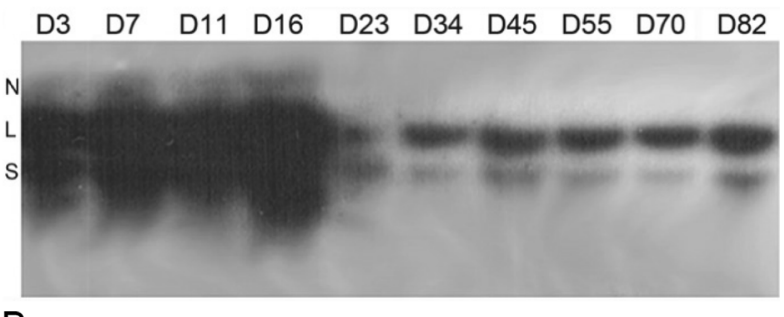

B Time course two $\begin{array}{lllllllllll}\text { D3 } & \text { D7 } & \text { D11 } & \text { D16 } & \text { D23 } & \text { D33 } & \text { D44 } & \text { D55 } & \text { D65 } & \text { D75 } & \text { D85 }\end{array}$

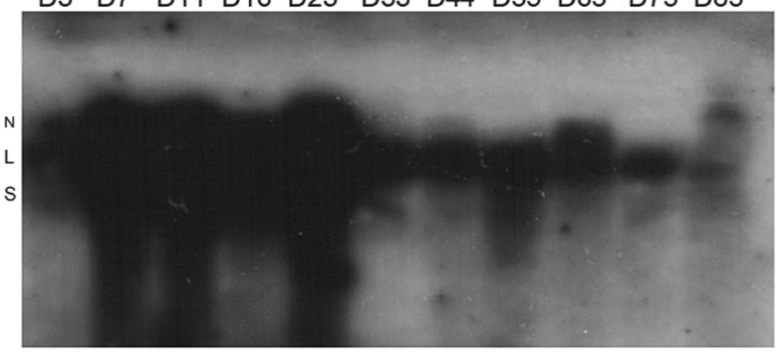

C Time course three

D3 D7 D11 D16 D23 D34 D45 D58 D72 D84 D95 D108

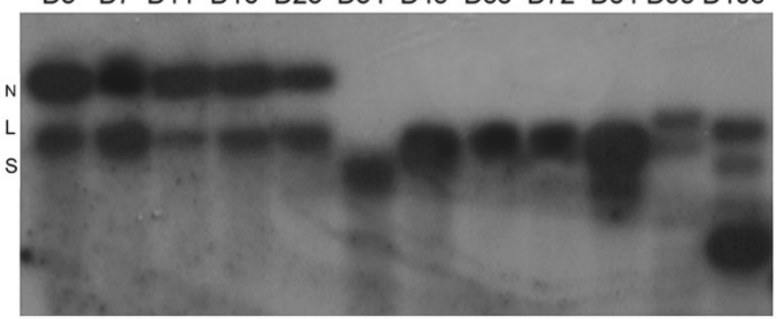

Fig. 1 BPV-1 DNA detected by Southern blot hybridization in BPV-1 virion-infected $S$. cerevisiae culture in three-time course experiments: day 0 to day $82(\mathbf{A})$, day 0 to day $85(\mathbf{B})$, day 0 to day $108(\mathbf{C}) . S$. cerevisiae cells $\left(10 \mathrm{~mL} ; 5 \times 10^{7}\right.$ cells $\left./ \mathrm{mL}\right)$ infected with $0.6 \mu \mathrm{g}$ of BPV-1 was cultured at $28{ }^{\circ} \mathrm{C}$ in the dark. At each time point, $5 \mathrm{~mL}$ of S. cerevisiae cells was collected for Hirt DNA preparation, with $5 \mathrm{~mL}$ of fresh medium added for continuous culture. $10 \mu \mathrm{g}$ of Hirt DNA without partial digestion of HindIII was electrophoresed on a $1 \%$ agarose gel and blotted onto a nylon membrane. Blots were hybridized with BPV-1 DNA using $\left[\alpha-{ }^{32} \mathrm{P}\right] \mathrm{dCTP}$ at $3000 \mathrm{Ci} / \mathrm{mmol}$ and exposed using Kodak BioMax film at $-70{ }^{\circ} \mathrm{C}$ for $24 \mathrm{~h}$. N, nicked circular BPV-1 DNA; L, linear BPV-1 DNA; S, supercoiled monomeric BPV-1 DNA

S. cerevisiae infected with BPV-1 virions could maintain episomal BPV-1 DNA for a long-term period. The results also suggested that the viral genome was actively amplified in the BPV-1-infected S. cerevisiae cells at the early stage, and then replicated at a low and constant copy number at the middle and late stages to establish persistent infection in the $S$. cerevisiae cells.

\section{DNA Replication Intermediates in Long-Term BPV-1-Infected S. cerevisiae Cultures}

We have previously confirmed that BPV-1 DNA detected in the short term BPV-1-infected S. cerevisiae culture at one-time point was replicating, with a single replication 
bubble observed, which was a typical replication pattern by 2-DAGE and Southern blot hybridization (Zhao and Frazer 2002a). Here, the Hirt DNA samples without HindIII digestion were used to carry out 2-DAGE and Southern blot hybridization to analyze newly synthesized viral genomic DNA. Most of the newly replicated duplex DNA was converted into small molecules: the replication intermediates, which served as the templates for additional replication or transcription. The generation of the replication intermediates of viral DNA over the time course could be divided into three culture stages: early (day 3-16), middle (day 23-34/45), and late-stage (day 45-82). At the early culture stage (day 3, 7, 11 and 16), much more multiple replication intermediates such as the linear monomers, dimers, trimers, and higher oligomers were generated and shown as covalently closed circles (CCC1, $\mathrm{CCC} 2, \mathrm{CCC} 3, \mathrm{CCC} 4$ and $\mathrm{CCC} 5)$ and open circles (OC1, OC2, OC3, OC4) (Fig. 2). The cccDNAs are the most important replication intermediates that serve as the main nuclear transcription template for producing all viral RNAs in the viral life cycle. Furthermore, the replication intermediates including $1 \mathrm{ss}, 2 \mathrm{ss}$ and lin consistently occurred at this stage (Fig. 2). Also, other replication intermediates such as hds, cms, RCR and RDR intermediates were detected (Fig. 2). Although so many different replication intermediates were detected, the occurrences of these intermediates except for $1 \mathrm{ss}, 2 \mathrm{ss}$ and lin forms were significantly different from one-time point to another time point. Generally, significantly more replication intermediates were detected in the early culture stage (day 3, 7, 11 and 16) than those in the middle culture stage (day 23 and 34) (Supplementary Fig. S2) and late culture stage (day 45, 55, 72 and 82) (Fig. 3). In fact, only 1ss, 2ss, lin and hds forms were present, other replication intermediates were scarcely detected in the middle culture stage (day 23 and 34) (Supplementary Fig. S2). It appeared that much less replication intermediates occurred in the middle stage were associated with poor growth of the BPV-1-infected $S$. cerevisiae cells (Supplementary Fig. S1) and poor replication status of the viral DNA (Fig. 1). In the late culture stage, replication intermediates such as $\mathrm{CCC} 1, \mathrm{CCC} 5$, OC1, OC2, OC3, OC4 and cms could be detected, but not as many as those observed at the early culture stage (Figs. 2 and 3). In addition, Y-shaped replication intermediates were observed at several time points in both early and late stages (Figs. 2 and 3).

\section{Diagrammatic Explanation of BPV-1 DNA Replication Intermediates in S. cerevisiae}

We have drawn a diagram to explain the identified replication intermediates of BPV-1 DNA in S. cerevisiae cells mainly based on the day-7 visualized 2-DAGE/Southern blotting result (Fig. 4). Firstly, the identified replication intermediates included $1 \mathrm{ss}, 2 \mathrm{ss}$, hds, lin and a series of oligomers. The size of $1 \mathrm{ss}$ was about $8 \mathrm{~kb}$ while the $2 \mathrm{ss}$ was approximately $16 \mathrm{~kb}$ and hds was over $23 \mathrm{~kb}$. The identified oligomers contained monomers, dimmers, trimers, and higher oligomers, which showed as CCC and OC. Both CCC and OC were detected above the arc of linear molecules, with their occurrences in different sizes associated with the arc numbers of linear molecules. Generally, the OC has shown a slightly higher molecular size than CCC within an arc of linear molecules. Then, the identified replication intermediates included RDR, RCR and cms. RDR is one of HPV DNA replication modes (Sakakibara et al. 2013). RDR occurred in a high molecular size is recognized as important for replication restart and stability, which plays an essential role in the replication cycle of HPV DNA. RCR is a single nicking event on one parental DNA strand, which gives rise to unidirectional replication resulting from the convergence of two replication forks without forming intermediates and termination structures (Flores and Lambert 1997). cms was detected under the arc of linear molecules and generated from the oligomerization of circular single-stranded DNA. cms is independent on the topology of the input DNA and has various molecular sizes due to rapid binding of E1 and slow dissociation (White et al. 2001).

\section{Discussion}

It has been established that PVs, the small double-stranded DNA viruses, infect epithelial tissue of their mammalian hosts and replicate in mitotically active basal keratinocytes in which the viral genomes are maintained as a nuclear plasmid (episome). Generally, viruses causing acute infections usually transform the infected cell into a virus factory, eventually leading to cell death and release of the viral progeny (Lipsitch and O'Hagan 2007). However, PVs do not kill the infected cell. Instead, PV infections persist mostly for decades but are not very productive (Cubie 2013). The PVs in persistently infected mammalian host epithelia rely upon the host replication machinery for their replications. However, it still lacks mammalian cell systems and an animal model for the vegetative replication of HPVs. We previously demonstrated that replication of BPV-1 DNA was present in virion-infected $S$. cerevisiae cells. Here we report further that episomal replication of BPV-1 DNA persistently present in virions-infected S. cerevisiae by long-term culture (up to 108 days). The persistent replication of BPV-1 DNA in $S$. cerevisiae is attributed to several physiological factors that DNA replication machinery is generally conserved between humans and S. cerevisiae (Chattopadhyay et al. 2005) and the 

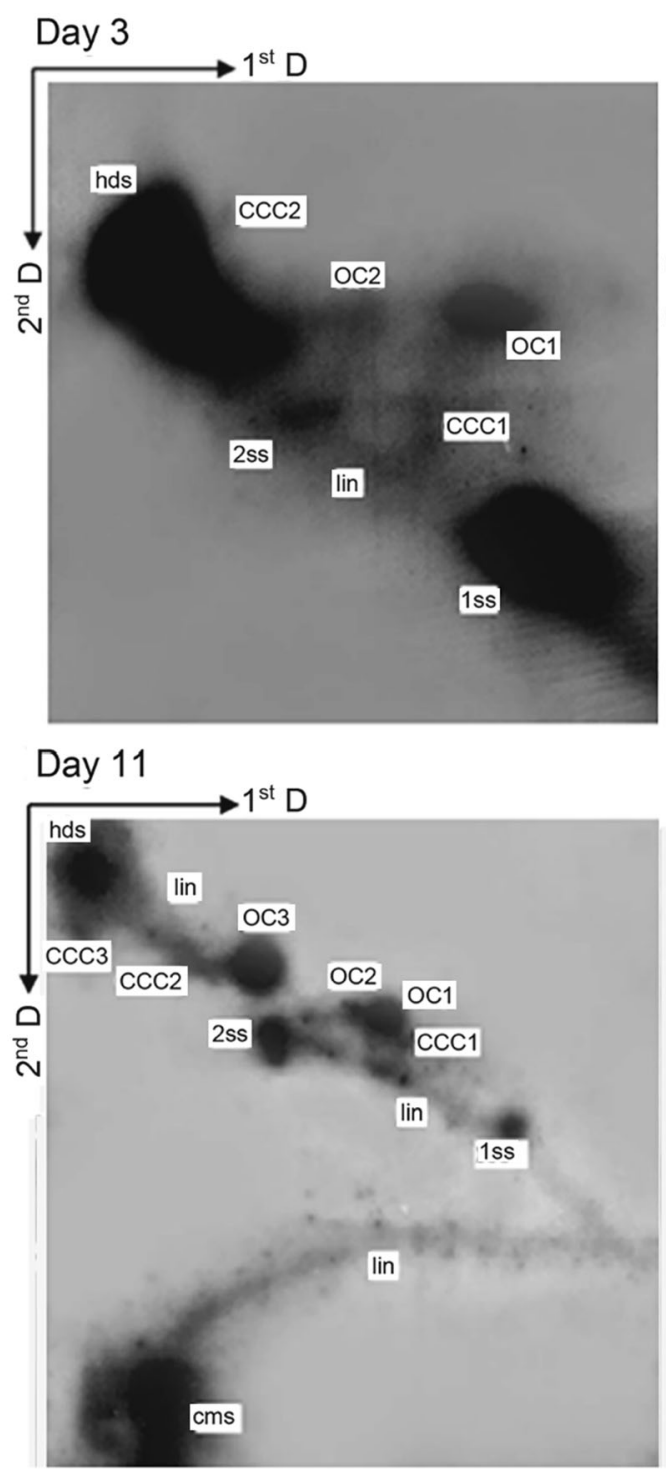

Fig. 2 Analysis of viral DNA replication intermediates in BPV-1 virion-infected $S$. cerevisiae cells culture for 3, 7, 11 and 16 days by means of two-dimensional gel electrophoresis. $15 \mu \mathrm{g}$ Hirt DNA was electrophoresed on a first-dimension agarose gel $(0.4 \%)$ in TAE buffer (40 mmol/L Tris-acetate, $2 \mathrm{mmol} / \mathrm{L}$ EDTA, $\mathrm{pH} 8.0$ ) at $1.5 \mathrm{~V} /$ $\mathrm{cm}$ for $20 \mathrm{~h}$. The DNA lanes were run on a second-dimension agarose gel $\left(1.0 \%\right.$ agarose in sterile distilled $\left.\mathrm{H}_{2} \mathrm{O}\right)$ in alkaline electrophoresis buffer $(40 \mathrm{mmol} / \mathrm{L} \mathrm{NaOH}, 2 \mathrm{mmol} / \mathrm{L}$ EDTA) at $1.5 \mathrm{~V} / \mathrm{cm}$ for $24 \mathrm{~h}$ and then blotted onto nylon membranes. The DNA blots were

cellular origin recognition (ORC) complex is functionally conserved from yeast to mammalian cells (Vashee et al. 2001). Also, PVs possess autonomously replicating sequence-like elements that control viral DNA replication (Rogers et al. 2008). The consensus ARS sequence within the BPV-1 genome shares with yeast (Chuang and Kelly 1999).

In our experiments, we extracted the episomal BPV DNA from the long-term virion-infected yeast cultures (up to 108 days), proved the episomal replication of BPV-1
Day 7

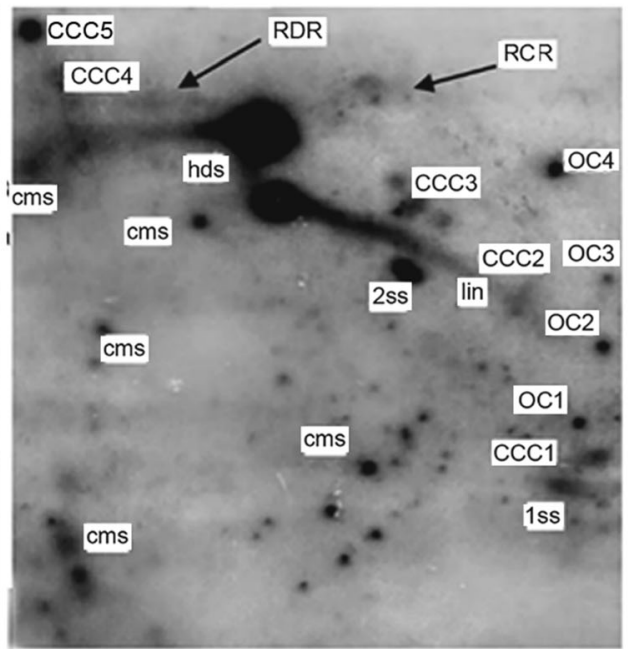

Day 16

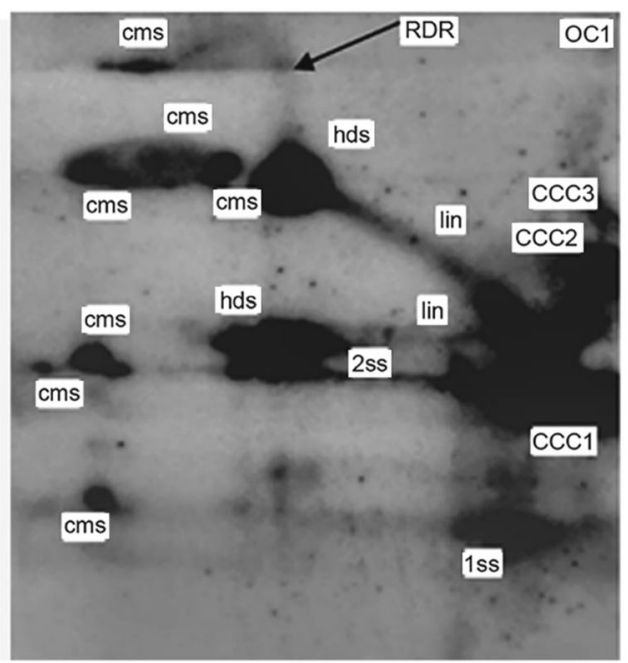

hybridized with a ${ }^{32} \mathrm{P}$-labeled BPV-1 DNA probe. Replication intermediates include single-stranded DNA (1ss), double-stranded DNA (2ss), heterogeneous double-stranded DNA (hds), linear forms (lin) and a series of oligomers. The oligomers contain monomers (1), dimers (2), trimers (3), and higher oligomers (4 or 5), which showed as covalently closed circles (CCC) and open circles (OC). Replication intermediates also include conspicuous multimeric circular ssDNA (cms), rolling circle replication (RCR) and recombinant-dependent replication $(\mathrm{RDR})$ intermediates.

DNA in yeast cells by 1-DAGE and DNA Southern blot hybridization. It was interested to note that the episomal replication of the BPV-1 DNA could be divided into three stages, active replication, weak replication and stable replication over the three-time courses. The active replication of the BPV-1 DNA at the early stage (up to 16 or 23 days) could be that the replicating molecules had a high degree of superspiralization in at least part of the replicating genome, due to the intensive ongoing elongation of the synthesized DNA strand. The weak replication of the 

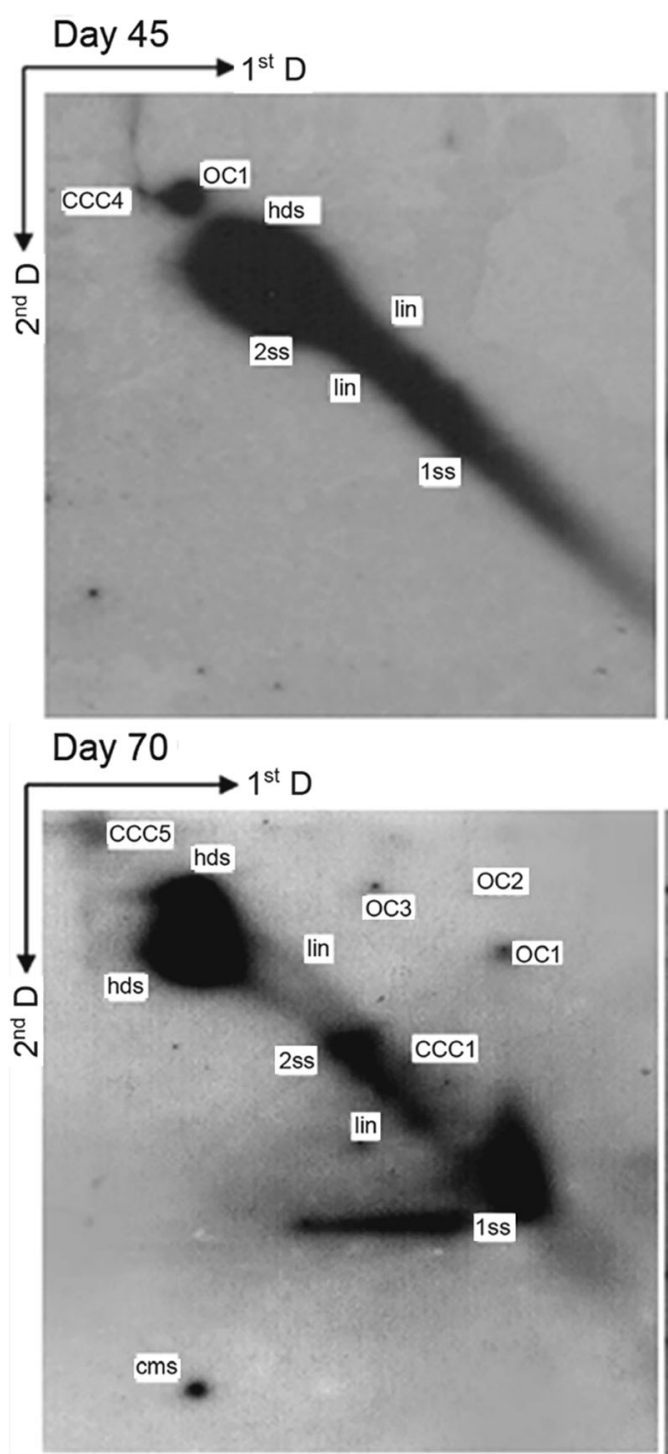

Fig. 3 Analysis of viral DNA replication intermediates in BPV-1 virion-infected $S$. cerevisiae cells culture for $45,55,70$ and 82 days by means of two-dimensional gel electrophoresis and Southern blothybridization analysis. Replication intermediates were detected

BPV-1 DNA in the middle stage (day 23-34 or 44) may be associated with that the replication of BPV-1 DNA could produce dramatic biochemical and structural changes, which might cause yeast cell damage. That may explain that the viral RNA transcription was very weak (Chen et al. 2021) and the virion-infected yeast cells grew slowly and unhealthy. At the late stage (day 45-108), the stable replication might be ascribed to the viral latency indicating that the BPV-1 virus was going to lie dormant within yeast cells, which was a typical characteristic shared by PVs (Araldi et al. 2017).

A previous study has reported that replication of BPV-1 genome in a subclone of 1ID13 mouse fibroblasts latently transformed with BPV-1 DNA occurs as a mixture of
Day 55

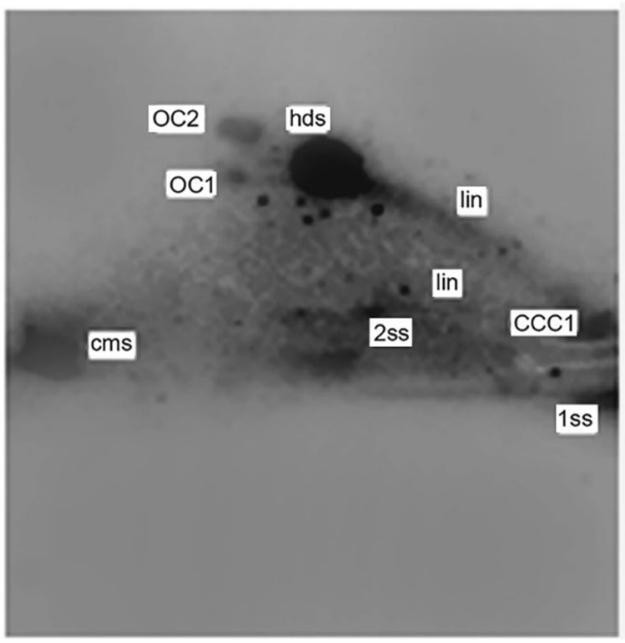

Day 82

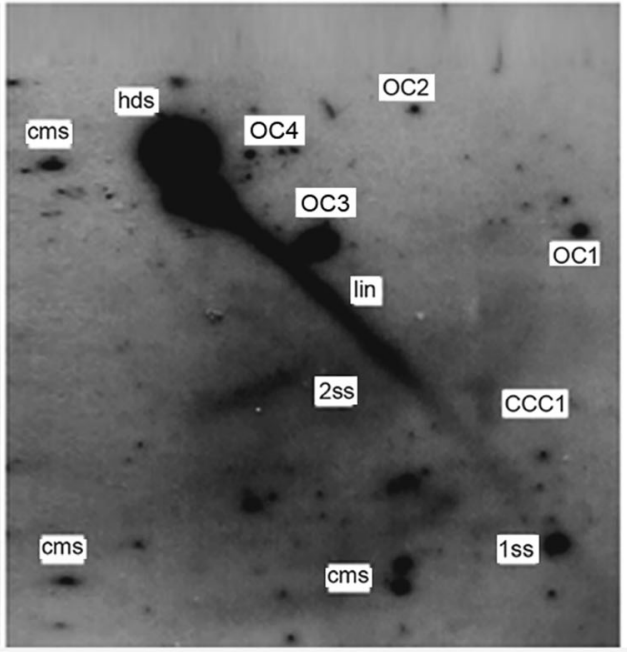

including not only single-stranded DNA (1ss), double-stranded DNA (2ss), heterogeneous double-stranded DNA (hds), linear forms (lin) but also a series of oligomers such as covalently closed circles (CCC), open circles (OC), conspicuous multimeric circular.

extrachromosomal circular monomers and oligomers (Schvartzman et al. 1990). However, no study has been reported to use real virions isolated from bovine papilloma to infect $S$. cerevisiae and mammalian cells and investigate the replication patterns and intermediates of the viral DNA. Previously, we observed that BPV-1 DNA partially digested with HindIII in the short-term BPV-1 virion-infected $S$. cerevisiae culture showed a single replication bubble, a typical replication pattern (Zhao and Frazer 2002a). In the present study, we investigated the replication patterns of BPV-1 DNA in BPV-1 infected $S$. cerevisiae culture over a long time period ( 82 days) by means of 2-DAGE and Southern blot hybridization. It has been reported that analysis of replication intermediates in 


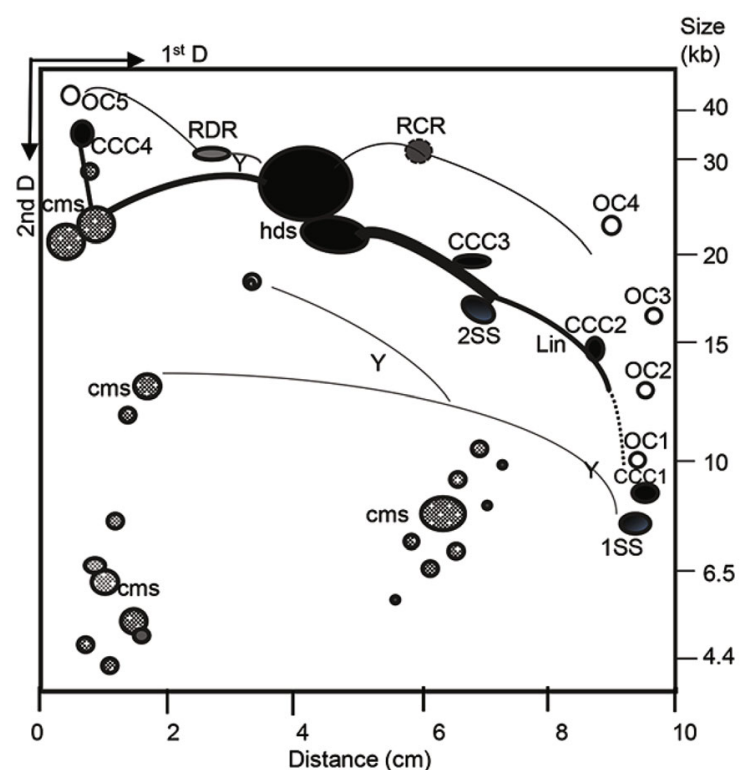

Fig. 4 Diagram of replication intermediates of BPV-1 DNA in BPV-1 virion-infected $S$. cerevisiae cells culture mainly based on the Day-7 visualized 2-DAGE/Southern blotting result (Fig. 2). The replication intermediates include single-stranded DNA (1ss), double-stranded DNA (2ss), heterogeneous double-stranded DNA (hds), linear forms (lin). The replication intermediates also include multiple oligomers that are covalently closed circles (CCC), open circles (OC), recombinant-dependent replication (RDR), rolling circle replication (RCR) and conspicuous multimeric circular ssDNA (cms). In addition, 2.3$\mathrm{kb}$ viral DNA fragment would be replicated by a single fork traversing the fragment $(\mathrm{Y})$ and by two converging forks $(\mathrm{Y})$ that met at the termination site for DNA replication.

HPV-18 might help to elucidate the complicated replication mechanisms of its viral DNA replication (Orav et al. 2015). Indeed, multiple replication intermediates have been detected in the present study. The detected replication intermediates including linear forms, single-stranded, double-stranded and heterogeneous double-stranded DNAs appeared to be the autonomous viral DNA strands, which were steady over the time period. The occurrences of the linear monomers, dimers, trimers, and higher oligomers occurred in S. cerevisiae may be well explained by a published study in mammalian cells (Schvartzman et al. 1990). Initiation of DNA replication of BPV-1 occurred near the centre of the EcoRI-BamHI $5.6 \mathrm{~kb}$ fragment. The EcoRI-BamHI $2.3 \mathrm{~kb}$ fragment replicated as a DNA molecule containing a termination site for DNA replication and also by means of a single fork traversing the fragment from one end to other. Thus, multiple copies of BPV-1 DNA occurred at a single site in a head-to-tail tandem array, a partial digestion with a restriction enzyme that cut the BPV-1 genome only once would generate a series of linear monomers, dimers, trimers, and higher oligomers (Schvartzman et al. 1990). The other replication intermediates such as conspicuous multimeric circular ssDNA, rolling circle replication and recombinant-dependent replication intermediates occurred in S. cerevisiae are very complex, which appear to be associated with the utilization of templates and their length (Erdmann, 2010; Erdmann et al. 2010). The Y-shaped replication intermediates containing branched molecules are probably due to a delayed fashion with a beginning of leftward replication (Belanger et al. 1996). Thus, the multiple replication intermediates detected in the present study may be ascribed to that BPV-1 has different replication modes in $S$. cerevisiae. Two replication modes: an ordered once-per-S-phase fashion and a random fashion have been reported for the replication of BPV-1 DNA in eukaryotic cells (Berg et al. 1986; Gilbert and Cohen 1987; Nallaseth and DePamphilis 1994; Ravnan et al. 1992).

In viruses such as hepatitis B virus (HBV) and hepadnaviruses, higher oligomer cccDNA is a key replication intermediate in the viral life cycle (Cheng et al. 2020; D'Arienzo et al. 2021; Li et al. 2017; Lucifora et al. 2017). The cccDNA persisted in the nucleus is a long-lived nucleosome-associated minichromosome, which is the main nuclear transcription template for producing all viral RNAs (Hong et al. 2017; Luo et al. 2020). Recently, covalently closed circular RNAs (cccRNAs) have been described in the human DNA tumor viruses Epstein-Barr virus (EBV) and Kaposi's sarcoma-associated herpesvirus (KSHV) (Toptan et al. 2018). In the present study, cccDNA was detected in the BPV-1 virion-infected $S$. cerevisiae cultures. However, the frequencies of cccDNA at the first stages (day 3-16) were significantly higher than those at the third stage (day 45-82) while the cccDNA appeared to be suppressed at the second stage (day 23-34) due to the unhealth growth of the virion-infected yeast cells. The high frequency of cccDNA at the first stage might directly contribute the high transcription of BPV-1 RNA (Chen et al. 2021). In addition, each time point at the third stage (day 45-82) that showed to have only one cccDNA occurred might suggest that replication of BPV-1 viral DNA was conserved to maintain its genomic DNA at low-copy numbers for the latent infection.

Recently, Toots and colleagues reported that several novel HR-HPV-specific inhibitors were identified to inhibit the HPV replication in the cells (Toots et al. 2017). These HR-HPV-specific inhibitors target Tdp1 and PARP1 leading to blocking HPV genome replication, colliding replication forks and eventually producing aberrant DNA replication intermediates (Toots et al. 2017). Thus, whether the identified HR-HPV-specific inhibitors could target BPV-1 L2 proteins, specifically the L2 CPP to prevent BPV genome replication leading to forming aberrant DNA replication intermediates is worthy of future study in BPV-1 virion-infected S. cerevisiae. 
In conclusion, we have shown three episomal replication patterns of BPV-1 genomic DNA in virion-infected S. cerevisiae for long-term cultures (up to 108 days) by means of DAGE and Southern blot hybridization. BPV-1 genome could replicate as extrachromosomal dsDNA circular plasmids and maintain stable copy numbers at the late stage in the virion-infected yeast cells. Our data have revealed that multiple replication intermediates detected include the linear monomers, dimers and trimers, higher oligomers especially cccDNAs, single-stranded DNA, double-stranded DNA, heterogeneous double-stranded DNA, multimeric circular ssDNA, rolling circle replication and recombinant-dependent replication intermediates. The occurrence of these viral replication intermediates will improve our understanding of BPV-1 genomic DNA replication in $S$. cerevisiae system.

Acknowledgements This work was funded in part by grants from the National Nature Science Foundation of China (81772791 and $81172463)$.

Author contributions $\mathrm{KNZ}$ conceived, designed, and supervised the study, and reviewed and revised the manuscript. QT, QL, WF, ZC, $\mathrm{YZ}$ and JC performed the experiments. PJ analysed data and drafted the manuscript. XX contributed to design and reviewed the data and manuscript. LZ supervised the study and reviewed the data and manuscript.

\section{Compliance with Ethics Guidelines}

Conflict of interest The authors declare that they have no conflict of interest.

Animal and Human Rights Statement This article does not contain any studies with human or animal subjects performed.

Open Access This article is licensed under a Creative Commons Attribution 4.0 International License, which permits use, sharing, adaptation, distribution and reproduction in any medium or format, as long as you give appropriate credit to the original author(s) and the source, provide a link to the Creative Commons licence, and indicate if changes were made. The images or other third party material in this article are included in the article's Creative Commons licence, unless indicated otherwise in a credit line to the material. If material is not included in the article's Creative Commons licence and your intended use is not permitted by statutory regulation or exceeds the permitted use, you will need to obtain permission directly from the copyright holder. To view a copy of this licence, visit http://creativecommons. org/licenses/by/4.0/.

\section{References}

Amtmann E, Sauer G (1982) Bovine papilloma virus transcription: polyadenylated RNA species and assessment of the direction of transcription. J Virol 43:59-66

Angeletti PC, Kim K, Fernandes FJ, Lambert PF (2002) Stable replication of papillomavirus genomes in Saccharomyces cerevisiae. J Virol 76:3350-3358
Araldi E, Chamorro-Jorganes A, van Solingen C, Fernandez-Hernando C, Suarez Y (2015) Therapeutic Potential of Modulating microRNAs in Atherosclerotic Vascular Disease. Curr Vasc Pharmacol 13:291-304

Araldi RP, Assaf SMR, Carvalho RF, Carvalho M, Souza JM, Magnelli RF, Modolo DG, Roperto FP, Stocco RC, Becak W (2017) Papillomaviruses: a systematic review. Genet Mol Biol 40:1-21

Belanger KG, Mirzayan C, Kreuzer HE, Alberts BM, Kreuzer KN (1996) Two-dimensional gel analysis of rolling circle replication in the presence and absence of bacteriophage $\mathrm{T} 4$ primase. Nucleic Acids Res 24:2166-2175

Bell L, Byers B (1983) Separation of branched from linear DNA by two-dimensional gel electrophoresis. Anal Biochem 130:527-535

Berg L, Lusky M, Stenlund A, Botchan MR (1986) Repression of bovine papilloma virus replication is mediated by a virally encoded trans-acting factor. Cell 46:753-762

Borzacchiello G, Roperto F (2008) Bovine papillomaviruses, papillomas and cancer in cattle. Vet Res 39:45

Borzacchiello G, Russo V, Gentile F, Roperto F, Venuti A, Nitsch L, Campo MS, Roperto S (2006) Bovine papillomavirus E5 oncoprotein binds to the activated form of the platelet-derived growth factor beta receptor in naturally occurring bovine urinary bladder tumours. Oncogene 25:1251-1260

Campo MS (2003) Papillomavirus and disease in humans and animals. Vet Comp Oncol 1:3-14

Campos SK (2017) Subcellular trafficking of the papillomavirus genome during initial infection: the remarkable abilities of minor capsid protein L2. Viruses 9:370

Carvalho RF, Sakata ST, Giovanni DN, Mori E, Brandao PE, Richtzenhain LJ, Pozzi CR, Arcaro JR, Miranda MS, Mazzuchelli-de-Souza J, Melo TC, Comenale G, Assaf SL, Becak W, Stocco RC (2013) Bovine papillomavirus in Brazil: detection of coinfection of unusual types by a PCR-RFLP method. Biomed Res Int 2013:270898

Chattopadhyay A, Schmidt MC, Khan SA (2005) Identification of a 450-bp region of human papillomavirus type 1 that promotes episomal replication in Saccharomyces cerevisiae. Virology 340:133-142

Chen J, Li Q, Feng W, Chen Z, Wang Q, Zhang L, Jiang P, Zhao KN (2021) A model for long-term infection of bovine papillomavirus type 1 in Saccharomyces cerevisiae. Acta Virol 65:192-199

Cheng J, Zhao Q, Zhou Y, Tang L, Sheraz M, Chang J, Guo JT (2020) Interferon alpha induces multiple cellular proteins that coordinately suppress hepadnaviral covalently closed circular DNA transcription. J Virol 94:e00442-e520

Chuang RY, Kelly TJ (1999) The fission yeast homologue of Orc4p binds to replication origin DNA via multiple AT-hooks. Proc Natl Acad Sci U S A 96:2656-2661

Cubie HA (2013) Diseases associated with human papillomavirus infection. Virology 445:21-34

D'Arienzo V, Ferguson J, Giraud G, Chapus F, Harris JM, Wing PAC, Claydon A, Begum S, Zhuang X, Balfe P, Testoni B, McKeating JA, Parish JL (2021) The CCCTC-binding factor CTCF represses hepatitis B virus enhancer I and regulates viral transcription. Cell Microbiol 23:13274

Dandjinou AT, Larrivee M, Wellinger RE, Wellinger RJ (2006) Twodimensional agarose gel analysis of DNA replication intermediates. Methods Mol Biol 313:193-208

DiGiuseppe S, Keiffer TR, Bienkowska-Haba M, Luszczek W, Guion LG, Muller M, Sapp M (2015) Topography of the human papillomavirus minor capsid protein L2 during vesicular trafficking of infectious entry. J Virol 89:10442-10452

Ding J, Doorbar J, Li B, Zhou F, Gu W, Zhao L, Saunders NA, Frazer IH, Zhao KN (2010) Expression of papillomavirus L1 proteins 
regulated by authentic gene codon usage is favoured in G2/Mlike cells in differentiating keratinocytes. Virology 399:46-58

Doorbar J (2016) Model systems of human papillomavirus-associated disease. J Pathol 238:166-179

Erdmann J (2010) Chasing HIV from its hiding place. Chem Biol 17:787-788

Erdmann JB, Shepherd DN, Martin DP, Varsani A, Rybicki EP, Jeske H (2010) Replicative intermediates of maize streak virus found during leaf development. J Gen Virol 91:1077-1081

Flores ER, Lambert PF (1997) Evidence for a switch in the mode of human papillomavirus type 16 DNA replication during the viral life cycle. J Virol 71:7167-7179

Frazer IH, Levin MJ (2011) Paradigm shifting vaccines: prophylactic vaccines against latent varicella-zoster virus infection and against HPV-associated cancer. Curr Opin Virol 1:268-279

Gagnon D, Fradet-Turcotte A, Archambault J (2015) A quantitative and high-throughput assay of human papillomavirus DNA replication. Methods Mol Biol 1249:305-316

Gilbert DM, Cohen SN (1987) Bovine papilloma virus plasmids replicate randomly in mouse fibroblasts throughout $\mathrm{S}$ phase of the cell cycle. Cell 50:59-68

He Z, Meng Q, Qiao J, Peng Y, Xie K, Liu Y, Cai X, Zhang J, Chen C (2016) Mixed nipple infections caused by variant of BPV3 and a putative new subtype of BPV in cattle. Transbound Emerg Dis 63:e140-143

Hong X, Kim ES, Guo H (2017) Epigenetic regulation of hepatitis B virus covalently closed circular DNA: Implications for epigenetic therapy against chronic hepatitis B. Hepatology 66:2066-2077

Huh WK, Joura EA, Giuliano AR, Iversen OE, de Andrade RP, Ault KA, Bartholomew D, Cestero RM, Fedrizzi EN, Hirschberg AL, Mayrand MH, Ruiz-Sternberg AM, Stapleton JT, Wiley DJ, Ferenczy A, Kurman R, Ronnett BM, Stoler MH, Cuzick J, Garland SM, Kjaer SK, Bautista OM, Haupt R, Moeller E, Ritter M, Roberts CC, Shields C, Luxembourg A (2017) Final efficacy, immunogenicity, and safety analyses of a nine-valent human papillomavirus vaccine in women aged 16-26 years: a randomised, double-blind trial. Lancet 390:2143-2159

Kawauchi K, Takahashi C, Ishihara R, Hatama S (2015) Development of a novel PCR-RFLP assay for improved detection and typing of bovine papillomaviruses. J Virol Methods 218:23-26

Koller LD, Olson C (1972) Observations on the antigen-antibody complex in bovine papillomatosis. Am J Vet Res 33:317-321

Lemacon D, Jackson J, Quinet A, Brickner JR, Li S, Yazinski S, You Z, Ira G, Zou L, Mosammaparast N, Vindigni A (2017) MRE11 and EXO1 nucleases degrade reversed forks and elicit MUS81dependent fork rescue in BRCA2-deficient cells. Nat Commun 8:860

Li X, Zhao J, Yuan Q, Xia N (2017) Detection of HBV covalently closed circular DNA. Viruses 9:139

Lipsitch M, O'Hagan JJ (2007) Patterns of antigenic diversity and the mechanisms that maintain them. J R Soc Interface 4:787-802

Lucifora J, Salvetti A, Marniquet X, Mailly L, Testoni B, Fusil F, Inchauspe A, Michelet M, Michel ML, Levrero M, Cortez P, Baumert TF, Cosset FL, Challier C, Zoulim F, Durantel D (2017) Detection of the hepatitis B virus (HBV) covalently-closedcircular DNA (cccDNA) in mice transduced with a recombinant AAV-HBV vector. Antiviral Res 145:14-19

Luo J, Luckenbaugh L, Hu H, Yan Z, Gao L, Hu J (2020) Involvement of Host ATR-CHK1 Pathway in Hepatitis B Virus Covalently Closed Circular DNA Formation. mBio 11: e03423-19

Makovets S (2013) Basic DNA electrophoresis in molecular cloning: a comprehensive guide for beginners. Methods Mol Biol 1054:11-43
Melo CA, Melo SA (2014) MicroRNA biogenesis: dicing assay. Methods Mol Biol 1182:219-226

Melo CA, Silva GS, Souza MM (2015) Establishment of the genomic in situ hybridization (GISH) technique for analysis in interspecific hybrids of Passiflora. Genet Mol Res 14:2176-2188

Modolo DG, Araldi RP, Mazzuchelli-de-Souza J, Pereira A, Pimenta DC, Zanphorlin LM, Becak W, Menossi M, de Cassia SR, de Carvalho RF (2017) Integrated analysis of recombinant BPV-1 L1 protein for the production of a bovine papillomavirus VLP vaccine. Vaccine 35:1590-1593

Moody CA, Laimins LA (2010) Human papillomavirus oncoproteins: pathways to transformation. Nat Rev Cancer 10:550-560

Munday JS, Thomson N, Dunowska M, Knight CG, Laurie RE, Hills S (2015) Genomic characterisation of the feline sarcoid-associated papillomavirus and proposed classification as Bos taurus papillomavirus type 14. Vet Microbiol 177:289-295

Nallaseth FS, DePamphilis ML (1994) Papillomavirus contains cisacting sequences that can suppress but not regulate origins of DNA replication. J Virol 68:3051-3064

Navarro B, Rubino L, Russo M (2004) Expression of the cymbidium ringspot virus 33-kilodalton protein in Saccharomyces cerevisiae and molecular dissection of the peroxisomal targeting signal. J Virol 78:4744-4752

Olavarrieta L, Martinez-Robles ML, Sogo JM, Stasiak A, Hernandez P, Krimer DB, Schvartzman JB (2002) Supercoiling, knotting and replication fork reversal in partially replicated plasmids. Nucleic Acids Res 30:656-666

Orav M, Geimanen J, Sepp EM, Henno L, Ustav E, Ustav M (2015) Initial amplification of the HPV18 genome proceeds via two distinct replication mechanisms. Sci Rep 5:15952

Quinet A, Lemacon D, Vindigni A (2017) Replication fork reversal: players and guardians. Mol Cell 68:830-833

Ravnan JB, Gilbert DM, Ten Hagen KG, Cohen SN (1992) Randomchoice replication of extrachromosomal bovine papillomavirus (BPV) molecules in heterogeneous, clonally derived BPVinfected cell lines. J Virol 66:6946-6952

Rogers AJ, Loggen M, Lee K, Angeletti PC (2008) Varying efficiency of long-term replication of papillomaviruses in Saccharomyces cerevisiae. Virology 381:6-10

Sakakibara N, Chen D, McBride AA (2013) Papillomaviruses use recombination-dependent replication to vegetatively amplify their genomes in differentiated cells. PLoS Pathog, 9:e1003321

Schvartzman JB, Adolph S, Martin-Parras L, Schildkraut CL (1990) Evidence that replication initiates at only some of the potential origins in each oligomeric form of bovine papillomavirus type 1 DNA. Mol Cell Biol 10:3078-3086

Thomson NA, Dunowska M, Munday JS (2015) The use of quantitative PCR to detect Felis catus papillomavirus type 2 DNA from a high proportion of queens and their kittens. Vet Microbiol 175:211-217

Toots M, Ustav M Jr, Mannik A, Mumm K, Tamm K, Tamm T, Ustav E, Ustav M (2017) Identification of several high-risk HPV inhibitors and drug targets with a novel high-throughput screening assay. PLoS Pathog 13:e1006168

Toptan T, Abere B, Nalesnik MA, Swerdlow SH, Ranganathan S, Lee N, Shair KH, Moore PS, Chang Y (2018) Circular DNA tumor viruses make circular RNAs. Proc Natl Acad Sci U S A 115:E8737-E8745

Vashee S, Simancek P, Challberg MD, Kelly TJ (2001) Assembly of the human origin recognition complex. J Biol Chem 276:26666-26673

White PW, Pelletier A, Brault K, Titolo S, Welchner E, Thauvette L, Fazekas M, Cordingley MG, Archambault J (2001) Characterization of recombinant HPV6 and 11 E1 helicases: effect of ATP on the interaction of E1 with E2 and mapping of a minimal helicase domain. J Biol Chem 276:22426-22438 
Zhang L, Zhao Y, Tu Q, Xue X, Zhu X, Zhao KN (2020a) The role of programmed cell death ligand-1/ programmed cell death-1 (PDL1/PD-1) in HPV-induced cervical cancer and potential for their use in blockade therapy. Curr Med Chem 27:1-16

Zhang P, Monteiro da Silva G, Deatherage C, Burd C, DiMaio D (2018) Cell-penetrating peptide mediates intracellular membrane passage of human papillomavirus L2 protein to trigger retrograde trafficking. Cell 174:1465-1476

Zhang P, Moreno R, Lambert PF, DiMaio D (2020b) Cell-penetrating peptide inhibits retromer-mediated human papillomavirus trafficking during virus entry. Proc Natl Acad Sci U S A 117:6121-6128

Zhao KN, Frazer IH (2002a) Replication of bovine papillomavirus type 1 (BPV-1) DNA in Saccharomyces cerevisiae following infection with BPV-1 virions. J Virol 76:3359-3364
Zhao KN, Frazer IH (2002b) Saccharomyces cerevisiae is permissive for replication of bovine papillomavirus type 1. J Virol 76:12265-12273

Zhao KN, Sun XY, Frazer IH, Zhou J (1998) DNA packaging by L1 and L2 capsid proteins of bovine papillomavirus type 1 . Virology 243:482-491

Zottnick S, Voss AL, Riemer AB (2020) Inducing immunity where it matters: orthotopic HPV tumor models and therapeutic vaccinations. Front Immunol 11:1750

zur Hausen H (2009) Papillomaviruses in the causation of human cancers - a brief historical account. Virology 384:260-265 